continue working despite pain. Very little is known about the factors contributing to or compromising the likelihood of these workers staying at work with pain.

Methods An interpretive descriptive method was used to explore factors associated with staying at work with pain. A transdisciplinary conceptual model was created, based on literature from the fields of work rehabilitation, ergonomics and demographics. Semi-structured individual interviews were conducted. Inclusion criteria were: blue collar workers, musculoskeletal pain (excluding cancer pain) for 6 months or more, and working 28 hours weekly or more. Analysis was performed using themes from the conceptual model; intra- and inter-case analysis was conducted using qualitative data analysis software.

Results Fifteen participants (7 women) were included, ages 55-70. They ranged from self-employed individuals to employees of large organisations, with half of them working in the private sector. Although all participants mentioned the importance of financial factors in their decision to stay at work, they did not generally consider it the main reason. For most, the perception of being useful, having peer recognition and feeling that work contributes to health were essential drivers for staying at work. Flexibility at work was deemed essential by all but took various forms.

Discussion This study identified, for the first time, both personal and work-related factors associated with working in the presence of pain. These results will help in developing better strategies to keep ageing workers at work.

\section{IS THERE AN INFLUENCE OF E-MAIL REGULATIONS ON THE PERCEIVED ACCESSIBILITY OF EMPLOYEES?}

W Fischmann*, A Voss, E Wischlitzki, N Amler, J Kiesel, H Drexler. Friedrich-AlexanderUniversity of Erlangen-Nürnberg, Germany

\subsection{6/oemed-2018-ICOHabstracts. 116}

Introduction The accessibility of employees beyond normal working time has increased considerably through the digitization of work and the use of digital media. The extent to which the resulting flexibility has an impact on the employees" health and whether a limitation might be helpful has not yet been clarified.

Methods Within the framework of a collaborative project ('RegioKMUnet'), funded by the German Federal Ministry of Education and Research this is examined among 12 small and medium-sized enterprises by means of psychological risk assessment (paper and online surveys) ( $\mathrm{N}$ [employees]=1802). The focus is on regulations in dealing with e-mails and the possible relation to satisfaction with accessibility in leisure time.

Results The evaluation refers to 9 companies so far $(n=1067)$. $28 \%$ of the employees stated that they had a regulation in dealing with e-mails on part of the company or personally. Further $37 \%$ did not consider it necessary to establish a regulation. 16\% had not yet thought about a regulation and 20\% had no regulation, as they otherwise feared disadvantages.

The accessibility outside working time was reported by $60 \%$ as 'okay'. Within this group, the majority (39\%) stated that an e-mail regulation was not necessary, followed by $23 \%$ who had a personally imposed regulation.

$23 \%$ considered the accessibility as 'not okay', of which $29 \%$ stated that an e-mail regulation was not necessary, followed again by $23 \%$ with a personal regulation.
Overall the group with a regulation in the company was the smallest (6\% each in ,okay' and ,not okay').

Conclusion An e-mail regulation does not appear to be the primary influencing factor on the perception of accessibility in leisure time. Further research is needed to examine different digital media and their impact in different industrial sectors.

\section{OCCUPATIONAL AND DEMOGRAPHIC RISKS OF ACCELERATED AGEING IN RUSSIAN WORKFORCE}

1,2Bashkireva Angelika*. 'Gerontological Centre of Leningrad Region, St. Petersburg, Russia; ${ }^{2}$ Research and Innovation Centre "Professional Longevity», St. Petersburg, Russia

\subsection{6/oemed-2018-ICOHabstracts.117}

Actual problems of workforce ageing in Russia are characterised by an increase in the mean worker's age and in the number of elderly workers, by the existence of job categories, where accelerated ageing is observed, as well as early retirement from work before reaching the retirement age. At the same time the demographic situation in Russia is characterised by the death-rate increase for all reason's classes, sharp premature mortality rise, extra-death-rate increase of workforce from affected reasons, the decrease in mean duration of human's forthcoming life. All these permanent factors in combination with the quantity increase of those in old and senile age may result in depopulation and workforce deficiency. These demographic processes lead to essentially significant increase of the demographic load coefficient on the society, which complicate the economic situation and produce considerable structural changes in employment, public assistance and nursing care maintenance of disabled people. If total number of population in Russia for last 12 years is shortened on 5 million people more then, the occupied number - on 12 million more then, i.e. loss of persons in working age overtake losses of population as a whole. The workforce death-rate in Russia exceeds a similar index in EU in 4,5 times. Analysis of gender differences in Russia has revealed an excess of men's death-rate in working age in 5-7 once in contrast with such beside women. An unprecedented result is formed now in Russia - a break-up in average life expectancies between men and women more then in 11 years. Consequently, average statistical Russian man does not live till a pension age, i.e. dies, being in working age. The data thus obtained show that health safety and work ability promotion in workforce is a state problem and consists of a lot priority aspects, one of which is accelerated ageing prevention.

\section{ACCELERATED AGEING PREVENTION AND WORK ABILITY PROMOTION BY USE OF THE INNOVATIVE GERONTOTECHNOLOGY «AGE-FRIENDLY WORKPLACES»}

1,2Bashkireva Angelika*. 'Gerontological Centre of Leningrad Region, St. Petersburg, Russia; ${ }^{2}$ Research and Innovation Centre "Professional Longevity», St. Petersburg, Russia

\subsection{6/oemed-2018-ICOHabstracts. 118}

Introduction In the conditions of demographic ageing, depopulation and workforce deficiency in Russia, the need of the employment of aged workers will grow every year. Timeliness and complexity of the solution of the employment problems among aged workers determines the expediency of the creation of a system for screening and monitoring work ability, 
with special age-oriented working conditions and jobs in various professional groups for the most rational employment of aged workers.

Methods We suggest an innovative methodological model for the preparation of jobs for aged workers, including not only modern hygienic requirements, but also criteria for the adequacy of jobs to the needs of aged workers, as well as integral criteria for the assessment of work ability and adaptability of aged workers to the functional, physiological and psycho-physiological work loads. The proposed model «AgeFriendly Workplaces» includes all stages of professional rehabilitation that allows to take into account individual features of the functioning of the organism of aged workers in strict accordance with their age, profession, availability and duration of work, motivation and work ability level.

Results A study of residual work ability among aged workers showed that $57.2 \%$ of workers « $45+»$ and $96.7 \%$ of workers «60+» need to use ergonomic innovations at work to compensate for the age-related decline in their performance. Cluster analysis revealed reliable differences in the mechanisms of formation of residual work ability among workers « $45+»$ and «60+». The correlations between residual work ability among aged workers « $60+»$ and indicators of their professional anamnesis were proved.

Conclusion The development and implementation of the age management system as one of the most fundamental in solving the employment problems of those in pre-retirement and retirement age will allow a more gentle and smooth approach to the issue of extending the working age in Russia.

\section{WORKING ENVIRONMENT AND WORK RETENTION OF AGEING WORKERS}

I Schaumburg*, O Melchior Poulsen*, LL Andersen*. National Research Centre for the Working Environment, Denmark

\subsection{6/oemed-2018-ICOHabstracts.119}

Introduction Demographic changes will profoundly decrease the fraction of the population being at working age in the Nordic countries. This will increase pressure on the Nordic welfare systems, and increased work participation and prolonged work life is therefore high on the political agenda. A recent project showed that the working environment has high impact on early retirement to both disability pension and voluntary pension. However, the project also revealed that knowledge is still lacking on working environment predictors of early retirement particularly in occupations with high risk of early retirement (e.g. blue collar workers with strenuous work).

Methods Data from the Danish 'Work Environment and Health' survey, which is performed every second year among a representative sample of wage earners between 18 and 64 years (50 806 persons in 2012; 50875 persons in 2014; and 65741 persons in 2016), will be analysed for cross-sectional and prospective associations between working environment and intention to retire early. Analyses will be adjusted for various confounders and stratified for socioeconomic position and selected larger job groups.

Results The Nordic project found the following working environment factors to be predictors of early retirement: Occupational accidents, whole-body vibration, physical work demands (strenuous work, heavy lifting, prolonged standing), quantitative work demands (work speed and time pressure), job control, influence at work, leadership support, conflicts at work, bullying/harassment, and job satisfaction. Results from analysis in 'Work Environment and Health' of the differential impact of the different working environment factors on intention to retire early in different occupations will be presented.

Conclusion The working environment factors of major importance for early retirement in occupations with high risk of early retirement are identified, and possible working environment interventions to improve work retention and prolong work-life are discussed.

\section{THE AGEING WORKFORCE, WOMEN AND THE IMPLICATIONS FOR OCCUPATIONAL SAFETY AND HEALTH}

SM Copsey* Elke Schneider. European Agency for Safety and Health at Work (EU-OSHA)

10.1136/oemed-2018-ICOHabstracts. 120

Introduction The workforce in the EU is ageing; therefore, age-related occupational safety and health (OSH) strategies are crucial. However, men and women face different age-related challenges and are differently affected by issues in the workplace throughout working life. In order to inform policy, debate and future research on sustainable work, it is important to identify and understand these differences.

Methods Published and 'grey' literature were reviewed. Case studies on retaining older workers featuring female-dominated work were described and analysed. Input was received from discussion at two European seminars. Issues explored included caring for relatives, the menopause, MSDs and incorporating a gender-sensitive approach into OSH and ageing workforce actions.

Results The key findings were:

- sex- and gender-related differences in working conditions persist throughout the working life; the cumulative physical and emotional impacts of women's work should not be underestimated;

- support is needed for risk assessments that incorporate the complexities of age and gender;

- long periods in low-level jobs, without career promotion, can lead to long-term exposure to hazards;

- equal access to rehabilitation and vocational training must be addressed;

- simple non-stigmatising workplace measures can support women going through the menopause;

- workplace health promotion strategies need different approaches for male and female audiences; flexible work measures need to be relevant to carers of elderly dependants and to both men and women;

- labour inspectorates should have clear diversity strategies;

- older female workers should be viewed as a valuable asset and the double discrimination that older female workers may face should be addressed through awareness raising.

Conclusion It is important to create sustainable working patterns for older workers, with a specific focus on older female workers, through measures that address workloads, work tasks, flexible working hours, the work-life balance, support in the workplace for specific gender-related health issues and workforce development. 